\title{
Protein Carbonyl Content
}

National Cancer Institute

\section{Source}

National Cancer Institute. Protein Carbonyl Content. NCI Thesaurus. Code C105825.

The presence of carbonyl derivatives of certain amino acids in a biological sample is indicative of protein oxidation. Oxidized proteins can be markers for oxidative stress. 